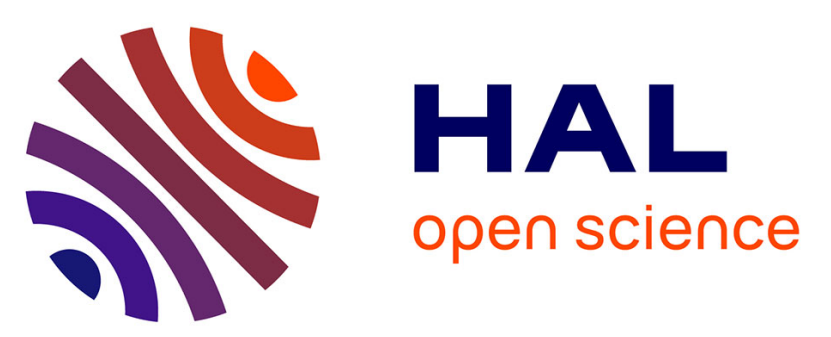

\title{
Identification and quantification of phosphatidylcholines containing very-long-chain polyunsaturated fatty acid in bovine and human retina using liquid chromatography/tandem mass spectrometry
}

Olivier Berdeaux, Pierre Juaneda, Lucy Martine, Stéphanie Cabaret, Lionel Brétillon, Niyazi Acar

\section{To cite this version:}

Olivier Berdeaux, Pierre Juaneda, Lucy Martine, Stéphanie Cabaret, Lionel Brétillon, et al.. Identification and quantification of phosphatidylcholines containing very-long-chain polyunsaturated fatty acid in bovine and human retina using liquid chromatography/tandem mass spectrometry. Journal of Chromatography, 2010, 1217 (49), pp.7738-7748. 10.1016/j.chroma.2010.10.039 . hal-01137063

\section{HAL Id: hal-01137063 https://hal.science/hal-01137063}

Submitted on 30 Mar 2015

HAL is a multi-disciplinary open access archive for the deposit and dissemination of scientific research documents, whether they are published or not. The documents may come from teaching and research institutions in France or abroad, or from public or private research centers.
L'archive ouverte pluridisciplinaire HAL, est destinée au dépôt et à la diffusion de documents scientifiques de niveau recherche, publiés ou non, émanant des établissements d'enseignement et de recherche français ou étrangers, des laboratoires publics ou privés. 


\section{Accepted Manuscript}

Title: Identification and quantification of phosphatidylcholines containing very-long-chain polyunsaturated fatty acid in bovine and human retina using liquid chromatography/tandem mass spectrometry

Authors: Olivier Berdeaux, Pierre Juaneda, Lucy Martine,

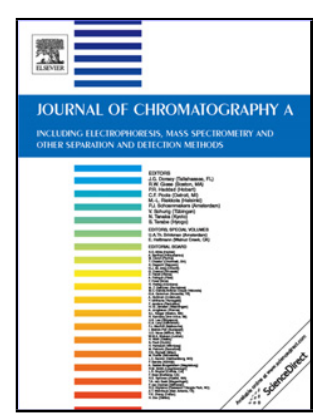
Stephanie Cabaret, Lionel Bretillon, Niyazi Acar

PII: S0021-9673(10)01402-0

DOI: doi:10.1016/j.chroma.2010.10.039

Reference: $\quad$ CHROMA 351468

To appear in: $\quad$ Journal of Chromatography A

Received date: $\quad 23-7-2010$

Revised date: $\quad$ 9-9-2010

Accepted date: $\quad$ 7-10-2010

Please cite this article as: O. Berdeaux, P. Juaneda, L. Martine, S. Cabaret, L. Bretillon, N. Acar, Identification and quantification of phosphatidylcholines containing very-long-chain polyunsaturated fatty acid in bovine and human retina using liquid chromatography/tandem mass spectrometry, Journal of Chromatography A (2008), doi:10.1016/j.chroma.2010.10.039

This is a PDF file of an unedited manuscript that has been accepted for publication. As a service to our customers we are providing this early version of the manuscript. The manuscript will undergo copyediting, typesetting, and review of the resulting proof before it is published in its final form. Please note that during the production process errors may be discovered which could affect the content, and all legal disclaimers that apply to the journal pertain. 


\section{Identification and quantification of phosphatidylcholines containing very-long-chain polyunsaturated fatty acid in bovine and human retina using liquid chromatography/tandem} mass spectrometry.

Olivier Berdeaux ${ }^{1 *}$, Pierre Juaneda ${ }^{2}$, Lucy Martine ${ }^{2}$, Stephanie Cabaret ${ }^{1}$, Lionel Bretillon ${ }^{2}$ and Niyazi Acar ${ }^{2}$

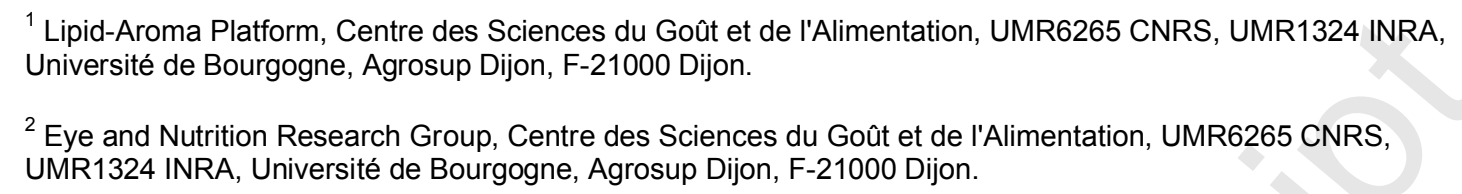

${ }^{1}$ Lipid-Aroma Platform, Centre des Sciences du Goût et de I'Alimentation, UMR6265 CNRS, UMR1324 INRA, Université de Bourgogne, Agrosup Dijon, F-21000 Dijon.

${ }^{2}$ Eye and Nutrition Research Group, Centre des Sciences du Goût et de l'Alimentation, UMR6265 CNRS, UMR1324 INRA, Université de Bourgogne, Agrosup Dijon, F-21000 Dijon.

\section{Address for Correspondence:}

13 Olivier Berdeaux, PhD

14 Centre des Sciences du Goût et de l'Alimentation,

15 Plate-Forme "Lipides-Arômes",

1617 , rue Sully, BP86510

1721065 Dijon Cedex

18 France

$19 \quad$ Fax $+33-(0) 3.80 .69 .32 .23$

20 Tel. $+33-(0) 3.80 .69 .35 .40$

21 E-mail: berdeaux@dijon.inra.fr 


\section{Abstract}

The retina is one of the vertebrate tissues with the highest content in polyunsaturated fatty acids (PUFA). A large proportion of retinal phospholipids, especially those found in photoreceptor membranes, are dipolyunsaturated molecular species. Among them, dipolyunsaturated phosphatidylcholine (PC) molecular species are known to contain very-long-chain polyunsaturated fatty acids (VLC-PUFA) from the $n-3$ and $n-6$ series having 24-36 carbon atoms (C24-C36) and four to six double bonds. Recent interest in the role played by VLC-PUFA arose from the findings that a protein called Elongation of very-long-chain fatty acids 4 (ELOVL4) is involved in their biosynthesis and that mutations in the ELOVL4 gene are associated with Stargardt-like macular dystrophy (STD3), a dominantly inherited juvenile macular degeneration leading to vision loss. The aim of the present study was to develop an HPLC-ESI-MS/MS method for the structural characterisation and the quantification of dipolyunsaturated PC molecular species containing VLC-PUFA and validate this methodology on retinas from bovines and human donors. Successful separation of phosphatidylethanolamine (PE), phosphatidylinositol (PI), phosphatidylserine (PS), PC, lysophosphatidylcholine (LPC) and sphingomyelin (SM) was achieved using a silica gel column and a gradient of hexane/isopropanol/water containing ammonium formate as a mobile phase. A complete structural characterisation of intact phosphatidylcholine species was obtained by collision-induced dissociation (CID) in the negative mode. Fatty acid composition and distribution can be clearly assigned based on the intensity of sn-2/sn-1 fragment ions. The PC species were characterised on bovine retina, 28 of which were dipolyunsaturated PC species containing one VLC-PUFA (C24-C36) with three to six double bonds. VLC-PUFA was always in the sn-1 position whilst PUFA at the sn-2 position was exclusively docosahexaenoic acid (DHA, C22:6n-3). Most of these VLC-PUFA-containing dipolyunsaturated PCs were detected and quantified in human retinas. The quantitative analysis of the different PC molecular species was performed in the positive mode using precursor ion scanning of $\mathrm{m} / \mathrm{z} 184$ and 14:0/14:0-PC and 24:0/24:0-PC as internal standards. The relationship between the MS peak intensities of different PC species and their carbon chain length was included for calibration. The main compounds represented were those having VLC-PUFA with 32 carbon atoms (C32:3, C32:4, C32:5 and C32:6) and 34 carbon atoms (C34:3, C34:4, C34:5 and C34:6). Dipolyunsaturated PCs with 36:5 and 36:6 were detected but in smaller quantities. In conclusion, this new HPLC-ESI-MS/MS method is sensitive and specific enough to structurally characterise and quantify all molecular PC species, including those esterified with VLC-PUFA. This technique is valuable for a precise characterisation of PC molecular species containing VLC-PUFA in retina and may be useful for a better understanding of the pathogenesis of STD3.

\section{Keywords:}

Phosphatidylcholines, Quantitative analysis, LC-ESI-MS/MS, Very-long-chain polyunsaturated fatty acids, Retina.

\section{Introduction}


The retina is one of the vertebrate tissues with the highest content of polyunsaturated fatty acids (PUFA). A large proportion of the retinal glycerophospholipids, especially those of photoreceptor membranes, consist of dipolyunsaturated molecular species. Studies have reported that dipolyunsaturated phosphatidylcholine (PC) molecular species present in both rod- and conedominant retinas contain $22: 6 n-3$ as one of the acyl chains, the other one being very-long-chain (C24C36) polyunsaturated fatty acids (four, five or six double bonds) [1-3]. The majority of these PC species containing VLC-PUFA (VLC-PC) are localised in photoreceptor outer segments where the phototransduction reactions take place [4]. In bovine photoreceptor outer segments, VLC-PC species are significant components of lipid membranes since the C28-C36 VLC-PUFA represent $10 \mathrm{~mol} \%$ of total fatty acids in PCs [1].

Recently, at least three different mutations in a gene called elongation of very long chain fatty acids 4 (ELOVL4) have been identified in patients with Stargardt-like macular dystrophy type 3 (STD3), a dominantly inherited form of juvenile macular degeneration leading to vision loss [5-8] Based on sequence homology with ELOVL1, 2, 3, and 5 proteins, which are implicated in the elongation of saturated, monounsaturated, or polyunsaturated fatty acids (PUFA) from 18 to 26 carbons, the ELOVL4 protein was predicted to have similar functions [5,8-11]. These findings suggested that retinal health depends on the presence of C28-C36 PUFA in addition to that of docosahexaenoic acid (DHA, C22:6n-3) [12].

Concurrently with these biochemical and molecular studies, a transgenic mouse model of STD3 carrying the human pathogenic 5-bp deletion in the mouse ELOVL4 gene was developed [13]. The animals displayed a retinal phenotype resembling that of human STD3, including an early selective deficiency in retinal C28-C36 acyl PCs, followed by a reduced electroretinographic response, an increased accumulation of toxic $N$-retinylidene- $N$-retinylethanolamine (A2E) and a degeneration of photoreceptor cells in the central retina. According to these findings, the proposed pathogenesis of human STD3 is based on the alteration of rod outer segments (ROS, corresponding to the distal part of retinal photoreceptor cells) composition in VLC-PUFA affecting phototransduction and leading to the accumulation of toxic A2E and further to photoreceptor death [14].

In order to confirm this hypothesis, dipolyunsaturated PC molecular species containing VLC-PUFA in retina must be precisely characterised to improve our understanding of the pathogenesis of STD3. Several current approaches were used for the characterisation and quantification of VLC-PUFA or VLC-PC in biological samples $[1,2,4,15,16]$, but most of these conventional approaches are timeconsuming, requiring successive extraction, chromatographic steps (HPLC, TLC) and often a derivatisation step before gas chromatography $(G C)$ or gas chromatography-mass spectrometry (GCMS) analyses. Electrospray ionisation-mass spectrometry (ESI-MS) has been described as a soft ionisation technology [17]. It is the most sophisticated and easiest technique for assessing the phospholipid content of a biological sample because of its high sensitivity and unmatched specificity. It directly analyses phospholipids as intact molecules and preserves the information based on the relative position of acyl radicals on the glycerol backbone. Using standard equipment, ESI-MS has been widely used for characterisation [17-23] and quantification of phospholipids [24-38]. Different approaches have been adopted for the analysis of molecular species of phospholipids using ESI-MS 
$[39,40]$. In some of these, crude lipid extracts were infused to the MS instrument and either direct MS scans or specific precursor ion or neutral loss scans were utilised to determine the different lipid species [29,34,36,39,41]. Other commonly used methods employed liquid chromatography with online mass spectrometric detection (HPLC-ESI-MS) [18,22,23,25-28,31,33,35,42-44]. The combination of high-performance liquid chromatography (HPLC) and ESI-MS reduces the ionisation suppression effect of low abundance PL species compared to indirect ESI-MS alone [24,43,45]. Moreover, HPLCESI-MS offers the advantage of a low spectral background signal [46]. However, the quantitative analysis of PL is not as easy since MS signals of PL are influenced by different effects related to acyl chain length, the degree of acyl chain unsaturation and concentration $[28,34,36]$.

In this study, we propose to develop a normal-HPLC-ESI-MS/MS method using a triple quadrupole mass spectrometer for precise characterisation and quantification of major PC species (including VLC$\mathrm{PC}$ and glyceroplasmenylcholine plasmalogen (PIsC) species) in total lipid extracts from bovine and human retinas. During the quantification step, particular attention was paid to the influence of different parameters related to PC acyl chain length and the degree of acyl chain unsaturation of the concentration on the spectrometer response according to previous studies $[27,34,36]$.

\section{Material and methods}

\subsection{Lipids and other materials}

All chemical reagents were purchased from Sigma-Aldrich (St Quentin Fallavier, France), chloroform and methanol from SDS (Peypin, France). HPLC-grade N-hexane, chloroform and isopropanol, LCMS-grade methanol and water were all from Fisher Scientific (Illkirch, France). Commercially available phospholipids were obtained from Avanti Polar Lipids Inc. (Alabaster, AL, USA): dimyristoyl-snglycerol-3-phosphatidylcholine (PC 14:0/14:0), 1,2-dipalmitoyl-sn-glycero-3-phosphocholine (PC 16:0/16:0), 1-palmitoyl-2-oleoyl-sn-glycero-3-phosphocholine (PC 16:0/18:1), 1,2-distearoyl-snglycero-3-phosphocholine (PC 18:0/18:0), 1-stearoyl-2-arachidonoyl-sn-glycero-3-phosphocholine (PC 18:0/20:4), 1-stearoyl-2-arachidonoyl-sn-glycero-3-phosphocholine (PC 18:0/20:4), 1-stearoyl-2docosahexaenoyl-sn-glycero-3-phosphocholine (PC 18:0/22:6), 1,2-diarachidoyl-sn-glycero-3phosphocholine (PC 20:0/20:0), 1,2-didocosahexaenoyl-sn-glycero-3-phosphocholine (PC 22:6/22:6), 1,2-dilignoceroyl-sn-glycero-3-phosphocholine (PC 24:0/24:0), 1-(1Z-octadecenyl)-2-oleoyl-sn-glycero3-phosphocholine (PLsC p180/18:1, where $\mathrm{p}$ refers to the ether-linked alcohol), 1-(1Z-octadecenyl)-2docosahexaenoyl-sn-glycero-3-phosphocholine (PLsC p180/22:6) and mixture PC molecular species of brain porcine.

\subsection{Lipid extraction}

Eyeballs were collected from a calf as well as from nine human donors according to a previously published procedure [47]. Samples from human cadavers were collected in accordance with the guidelines of the Declaration of Helsinki. Human eyeballs were obtained from 9 donors (bodies donated to science, five women and four men; mean age, $84.3 \pm 8.5$ years; range, $72-97$ years) within $16 \mathrm{~h}$ (median time, mean time $15 \pm 7 \mathrm{~h}$ ) after death. The bodies were refrigerated at $4^{\circ} \mathrm{C}$ in the first hours after death (less than $24 \mathrm{~h}$ ). Eyeballs were enucleated at the anatomy laboratory of the 
Saint-Etienne School of Medicine (France). Enucleated eyeballs were immersed in balanced salt solution (BSS, Alcon, Rueil Malmaison, France) at $4^{\circ} \mathrm{C}$. Within 30 min after enucleation, a circular section at the pars plana was taken with an 18-mm-diameter trephine and the corneoscleral disc removed for other studies. The posterior pole was placed on a back-lit table and the retina was observed under an operating microscope to select the tissue included in this study. Eyes with large drusen or severe pigment epithelial alterations, severe macular atrophy, macular hemorrhage, or any grossly visible chorioretinal pathologic abnormality were excluded. The vitreous body was carefully removed. The entire neural retina was carefully separated with forceps. Samples were stored at $-80^{\circ} \mathrm{C}$ under argon atmosphere. Total lipids were extracted from retinas according to the method described by Folch et al. (1957) [48]. The phosphorus content of the total phospholipid extract was determined according to the method developed by Bartlett and Lewis [49]. The total phospholipids were dried under a stream of nitrogen, after which internal standards PC 14:0/14:0 (final concentration, $0.4 \mathrm{ng} / \mathrm{\mu L}$ ) and PC 24:0/24:0 (final concentration, $0.64 \mathrm{ng} / \mathrm{\mu L}$ ) were added at about $30 \%$ of the major PC molecular species. The samples were then diluted to the appropriate concentration of $12.5 \mathrm{ng} / \mathrm{\mu L}$ in chloroform/methanol $(1: 1, \mathrm{v} / \mathrm{v})$ for analysis and stored at $-80^{\circ} \mathrm{C}$ under argon atmosphere.

\subsection{LC-ESI-MS using triple-quadrupole mass spectrometer}

The total phospholipids were analysed by liquid chromatography coupled to a mass spectrometer equipped with an ESI source. HPLC was performed using a JASCO PU 2089 Plus LC pump equipped with a JASCO AS 2057 Plus auto-sampler from JASCO Analytical Instruments (Bouguenais, France). The injection volume was $5 \mu \mathrm{L}$. The separation was performed using a Hypersil Silica Column (150 $\mathrm{mm} \times 2.1 \mathrm{~mm}$, i.d. $\times 3 \mu \mathrm{m}$ ) from ThermoFinnigan (San Jose, CA, USA). The mobile phase consisted of (A) hexane/2-propanol/chloroform/water (44/43.5/10.5/2, v/v/v/v) containing $12.5 \mathrm{mM}$ of ammonium formate and (B) hexane/2-propanol/chloroform/water (34/49/10.5/6.5, v/v/v/v) containing $12.5 \mathrm{mM}$ of ammonium formate. The solvent-gradient system comprised as follows: 0 min A/B (\%) 100/0, 10.5-24 $\min A / B(\%) 22 / 78,26.5-45 \mathrm{~min} A / B(\%)$ 0/100\% and 46-60 min A/B (\%) 100/0. The flow rate was 300 $\mu \mathrm{L} \cdot \mathrm{min}^{-1}$ and the column was maintained at $30^{\circ} \mathrm{C}$. The flow from LC was split using an analytical fixed flow splitter (split ratio $=1: 1$, post-column) from Analytical Scientific Instruments (El Sobrante, CA, USA). Mass spectrometry was performed using a ThermoFinnigan TSQ Quantum triple quadrupole mass spectrometer equipped with a standard electrospray ionisation source outfitted with a $100-\mu \mathrm{m}$ i.d. H-ESI needle. The source spray head was oriented at a $90^{\circ}$ angle orthogonal to the ion-transfer tube. Nitrogen was used for both the sheath and the auxiliary gases. The MS signals of PC species were first optimised by continuous infusion of the standards dissolved in the mobile phase using ESI in negative and positive modes. The electrospray ionisation spray voltages were $3 \mathrm{kV}$ and $-4.5 \mathrm{kV}$ in negative and positive ion modes, respectively, vaporiser temperature was $150^{\circ} \mathrm{C}$, sheath gas $\mathrm{N}_{2}$ pressure 45 (arbitrary units), auxiliary gas pressure 45 (arbitrary units), ion sweep gas pressure 5 , ion transfer capillary temperature $300^{\circ} \mathrm{C}$, skimmer offset $5 \mathrm{~V}$ and multiplier gain 300,000 .

When operated under full scan conditions in the negative and positive ion modes, data were collected in the range of $m / z 400-1100$ with a scan time of $0.5 \mathrm{~s}$. For PC characterisation in the negative mode, ESI-MS/MS was used with argon as the collision gas at $1.5 \mathrm{mTor}$, and the collision energy was set to 
$15 \mathrm{eV}$; in the positive mode, the collision gas pressure was $0.8 \mathrm{mTor}$ and the collision energy ranged from 30 to $45 \mathrm{eV}$. PC species were manually identified with the parent mass information and their characteristic fragment ions in the CID spectrum using lists of PL species prepared in our laboratory.

For PC quantification in ESI/MS/MS, precursor scanning at $m / z 184$ was used. Optimum conditions for collision-induced dissociation (CID) were selected. For all calculations, the ratio of peak area of each PC species to the peak area of the internal standards (PC 14:0/14:0 and PC 24:0/24:0) was used. Corrections are applied to the data for isotopic overlap. The data were processed using the Xcalibur software (ThermoFinnigan).

\subsection{Preparation of fatty acid methyl esters}

The fatty acid methyl esters (FAMEs) were prepared using the boron trifluoride $\left(\mathrm{BF}_{3}\right)$ reagent as the catalyst according to Morrison and Smith [50]. Briefly, lipids (up to $20 \mathrm{mg}$ ) were transferred to a centrifuge tube with a PTFE-lined screw cap and evaporated under a stream of nitrogen; $0.3 \mathrm{~mL}$ of toluene and $0.7 \mathrm{~mL}$ of boron trifluoride reagent $\left(\mathrm{BF}_{3} /\right.$ methanol, $\left.7 \%\right)$ were added under nitrogen and the tube was closed with the screw cap. The tube was then heated to $95^{\circ} \mathrm{C}$ for $2 \mathrm{~h}$ and then cooled to room temperature. FAMEs were extracted by adding $5 \mathrm{~mL}$ of saturated solution of $\mathrm{NaHCO}_{3}$ and $3 \times 2$ $\mathrm{mL}$ of hexane. The mixture was centrifuged $(3000 \mathrm{rpm})$ for $3 \mathrm{~min}$ to break the emulsion formed. After drying the organic phase over sulfate sodium $\left(\mathrm{Na}_{2} \mathrm{SO}_{4}\right)$, the solvent was removed under a stream of nitrogen and FAMEs were dissolved in hexane for $\mathrm{GC}$ analysis.

\subsection{Gas-chromatography analysis}

FAMEs $(0.5 \mathrm{mg} / \mathrm{mL}$ in hexane) were analysed on a Hewlett Packard Model 4890 gas-chromatograph (Palo Alto, CA, USA) using a CP-Sil $88(100 \mathrm{~m} \times 0.25 \mathrm{~mm}$ I.D. capillary column, $0.2 \mu \mathrm{m}$ film, Varian, Courtaboeuf, France). The instrument was equipped with a split/splitless injection (splitless for 0.5 $\mathrm{min}$ ). The linear velocity of hydrogen was $37.0 \mathrm{~cm} / \mathrm{s}$ at $60^{\circ} \mathrm{C}$. The temperature was held at $60^{\circ} \mathrm{C}$ for 5 min, raised to $165^{\circ}$ at $15^{\circ} \mathrm{C} / \mathrm{min}$ and held for $1 \mathrm{~min}$ and then to $225^{\circ} \mathrm{C}$ at $2 \%$ min and finally held at $225^{\circ} \mathrm{C}$ for $17 \mathrm{~min}$ according to the procedure described in the literature [51]. The injection port was held at $250^{\circ} \mathrm{C}$ and a flame ionisation detector (FID) was used at $250^{\circ} \mathrm{C}$.

\subsection{Preparation of 4,4-dimethyloxazoline derivatives}

FAME (up to $2 \mathrm{mg}$ ) were converted to the 4,4-dimethyloxazoline (DMOX) derivatives by treatment with $250 \mu \mathrm{L}$ of 2-amino-2-methyl-1-propanol in a test tube at $170^{\circ} \mathrm{C}$ overnight in a nitrogen atmosphere [52]. The reaction mixture was cooled and dissolved in $3 \mathrm{~mL}$ of dichloromethane and further washed twice with $5 \mathrm{~mL}$ of water. After drying the organic phase over $\mathrm{Na}_{2} \mathrm{SO}_{4}$, the solvent was removed under a stream of $\mathrm{N}_{2}$ and the sample was dissolved in hexane for GC-MS analysis.

\subsection{Gas-chromatography mass-spectrometry}

GC-MS analyses of DMOX derivatives were carried out on an Agilent 6890 series II gas chromatograph attached to an Agilent model $5973 \mathrm{~N}$ selective quadrupole mass detector (Palo Alto, CA, USA) operating in the electronic ionisation mode under an ionisation voltage of $70 \mathrm{eV}$ at $230^{\circ} \mathrm{C}$. Agilent ChemStation software was used for data acquisition and processing. The injector (splitless 
mode) and the interface temperature were maintained at $250^{\circ} \mathrm{C}$, whereas helium was used as the carrier gas under constant flow at $1 \mathrm{~mL} / \mathrm{min}$. Spectral data were acquired over a mass range of 50 $600 \mathrm{amu}$. GC separation was performed on a BPX-70 $(60 \mathrm{~m} \times 0.25 \mathrm{~mm}$ I.D. capillary column, $0.25 \mu \mathrm{m}$ film; SGE, Melbourne, Australia). The temperature was held at $60^{\circ} \mathrm{C}$ for $1 \mathrm{~min}$, raised to 240 at $20^{\circ} \mathrm{C} / \mathrm{min}$ and held at $240^{\circ} \mathrm{C}$ for $90 \mathrm{~min}$.

\section{Results and discussion:}

The objective of the present study was to develop a sensitive and specific method for the characterisation and quantification of PC species and in particular VLC-PC species in human retina using LC-ESI-MS/MS. Given the greater availability of bovine retinas compared to human retinas, the former were used by means of characterisation of VLC-PC. Bovine retina is also known to contain VLC-PUFA (C24-C36), specifically concentrated in PC [2].

\subsection{Separation of phospholipid classes}

We chose to separate the phospholipid species using LC prior to the ESI-MS/MS analysis in order to enhance the detection of the minor isobaric species in the mixture. Additionally, a suitable chromatographic separation may reduce any ESI suppression of non-isobaric and co-eluting species. Then we developed a normal-phase HPLC separation of phospholipid (PL) classes in order to separate and study the collision-induced dissociation of these PC molecular species containing VLCPUFA using a triple-quadrupole instrument.

Phospholipid species are zwitterionic molecules. Therefore either positive- or negative-ion mass spectra of these phospholipid classes were accessible through ESI-MS analysis. However, negativeion ESI mass spectra of phosphatidylethanolamine (PE), lyso-phosphatidylethanolamine (LPE), phosphatidylinositol (PI) and phosphatidylserine (PS) species only contain the $[\mathrm{M}-\mathrm{H}]^{-}$ion and were far more sensitive than positive-ion spectra [20]. In contrast, PC, lyso-phosphatidylcholine (LPC) and sphingomyelin (SM) species were more efficiently analysed in the positive-ion mode by generating protonated $[\mathrm{M}+\mathrm{H}]^{+}$ions but might also produce sodiated adduct $[\mathrm{M}+\mathrm{Na}]^{+}$ions. Only during the development of LC separation of total phospholipids was the mass spectrometer operated under full scan conditions in the negative ion mode for detection of PE, PI, PS and LPE and under full scan conditions in the positive ion mode for quantification of PC, LPC and SM species. A mobile phase consisting of hexane/isopropanol/chloroform/water for HPLC separation of PL classes on silica columns has been reported to give good separation for some PLs [53,54]. However, since PI and PS as well as PC and SM eluted very closely, class determination was far more complicated. In our study, ammonium formate was added to this mobile phase system to enhance separation, resolution and selectivity. By optimising the concentration of ammonium formate in the mobile phase, the flow rate and the use of a pertinent gradient, a good baseline separation of PE, PI, PS, PC, SM and LPC classes in bovine and human retinas was achieved, as illustrated in Fig. 1. The method did not require fractionation into neutral lipids and phospholipids. Total lipid extracts from retinas can be injected directly into the system, with neutral lipids eluting with the solvent front. As expected, plasmenylcholine (PIsC) species co-eluted with PC species. Moreover, under our HPLC conditions, VLC-PC molecular species containing VLC-PUFA eluted separately just before other PC molecular 
species, between 15.5 and $17 \mathrm{~min}$. Also, it was possible to collect this fraction in order to concentrate VLC-PC for further structure characterisation using GC-MS.

\subsection{Determination of PC species based on their specific fragmentation mechanisms}

Detailed structural analysis of glycerophospholipids can be performed using electrospray tandem mass spectrometry (ESI-MS/MS). Collision-induced dissociation (CID) of $[\mathrm{M}+\mathrm{H}]^{+}$or $[\mathrm{M}-\mathrm{H}]^{-}$of phospholipids results in fragment ions that are related to the polar head group and fatty acyl substituent esterified to the glycerol backbone.

In order to characterise PC molecular species, lipid extracts from bovine retina were analysed by ESIMS/MS in the positive and negative modes. Mass spectra obtained by CID of PC molecular ions were compared with those obtained from commercial standards. When operated in the single-stage MS mode using $\mathrm{ESI}$ in the positive ionisation mode, $\mathrm{PC}$ molecular species produced abundant $[\mathrm{M}+\mathrm{H}]^{+}$ions as well as sodiated $[\mathrm{M}+\mathrm{Na}]^{+}$ions [18]. The $\mathrm{MS}^{2}$ fragmentation of the selected $[\mathrm{M}+\mathrm{H}]^{+}$molecular ion of $\mathrm{PC}$ and PIsC gave an intense fragment at $\mathrm{m} / \mathrm{z} 184$ derived from phosphocholine head $\left[\mathrm{C}_{5} \mathrm{H}_{13} \mathrm{NPO}_{4}\right]^{+}$. When operated in the single-stage MS mode in the negative mode ionisation, PC molecular species produced abundant demethylated molecule $\left[\mathrm{M}-\mathrm{CH}_{3}\right]^{-}$ions (base peak). Molecular ions $[\mathrm{M}-\mathrm{H}]^{-}$were not detected. Under our HPLC conditions with chloroform and ammonium formate, chloride- $[\mathrm{M}+\mathrm{Cl}]^{-}$ and formate- $[\mathrm{M}+\mathrm{HCOO}]^{-}$adducts were also produced. By increasing the skimmer-off set value from 5 to $25 \mathrm{~V}$, it was possible to reduce these two adducts. The $\mathrm{MS}^{2}$ experiment of the selected $\left[\mathrm{M}-\mathrm{CH}_{3}\right]^{-}$ of PC species gave a characteristic fragmentation. As an example, for PC 16:0/18:1 (Fig. 2A), the $\mathrm{MS}^{2}$ fragmentation of the selected molecular ion $\left[\mathrm{M}-\mathrm{CH}_{3}\right]^{-}$at $\mathrm{m} / \mathrm{z} 744$ showed two prominent ions derived from the carboxylate anions at $m / z 281$ (major) and $m / z 255$ (minor), which correspond to the C18:1 and C16:0 fatty acyl substituent, respectively. Elimination of the fatty acyl substituent $\mathrm{C} 18: 1$ and $\mathrm{C} 16: 0$ leads to the formation of very minor fragments at $\mathrm{m} / \mathrm{z} 462$ and $\mathrm{m} / \mathrm{z} 488$, corresponding to the [M $\left.-\mathrm{CH}_{3}-\mathrm{R}_{2} \mathrm{CHCOOH}\right]^{-}$and the $\left[\mathrm{M}-\mathrm{CH}_{3}-\mathrm{R}_{1} \mathrm{CHCOOH}\right]^{-}$ions respectively. Two other fragments at $\mathrm{m} / \mathrm{z} 480$ and $\mathrm{m} / \mathrm{z} 506$ were also detected in slightly greater amounts than fragments at $\mathrm{m} / \mathrm{z} 462$ and $\mathrm{m} / \mathrm{z}$ 488. These fragments corresponded to the $\left[\mathrm{M}-\mathrm{CH}_{3}-\mathrm{R}_{2} \mathrm{CH}=\mathrm{C}=\mathrm{O}\right]^{-}$and the $\left[\mathrm{M}-\mathrm{CH}_{3}-\right.$ $\mathrm{R}_{1} \mathrm{CH}=\mathrm{C}=\mathrm{O}^{-}$ions, respectively, resulting from the loss of fatty acyl groups such as ketenes [19,21]. According to some authors, acyl chain distribution in phospholipids can be accurately determined with a triple-quadrupole spectrometer. The intensity of the carboxylate anion derived from the sn-2 acyl substituent is greater than the carboxylate anion derived from the $s n-1$ acyl substituent $[18,19]$. However, under our conditions, it was not verified with PC containing an LC-PUFA in position sn-2, e.g. $\mathrm{C} 20: 4 n-6$ (Fig. 2B) or C22:6n-6 (Fig. 2C). Indeed when $\mathrm{R}_{2} \mathrm{CH}_{2} \mathrm{COOH}$ was an LC-PUFA, a fragment was also detected at a mass $44 \mathrm{Da}$ lower than the carboxylate anion $\left[\mathrm{R}_{2} \mathrm{CH}_{2} \mathrm{COO}\right]^{-}$. This fragment is generated by the loss of one $\mathrm{CO}_{2}$ molecule from this LC-PUFA carboxylate anion. For example, the $\mathrm{MS}^{2}$ fragmentation of the selected molecular ion $\left[\mathrm{M}^{-} \mathrm{CH}_{3}\right]^{-}$at $\mathrm{m} / \mathrm{z} 794$ of $\mathrm{PC} 18: 0 / 20: 4$ showed two prominent ions at $\mathrm{m} / \mathrm{z} 283$ (C18:0 carboxylate anion) and m/z 303 (C20:4 carboxylate anion) and a lower fragment at $\mathrm{m} / \mathrm{z} 259$ generated by $\mathrm{CO}_{2}$ loss by the $\mathrm{C} 20: 4$ carboxylate anion. In the case of PC 18:0/22:6, the fragment at $\mathrm{m} / \mathrm{z} 327$ was decreased by the loss of one $\mathrm{CO}_{2}$ molecule from the C22:6 carboxylate anion, while the fragment at $m / z 283$ was increased because it was the sum of 
two fragments: the C18:0 carboxylate anion and the ion formed by the loss of $44 \mathrm{Da}$ from the C22:6 carboxylate anion. Consequently, the intensity of the C18:0 carboxylate anion derived from the sn-1 acyl substituent was greater than the C22:6 carboxylate anion derived from the sn-2 acyl substituent. In contrast, the regiospecificity of the acyl moieties in asymmetrical PC, even with a LC-PUFA in the $s n-2$ position, can be confirmed from the packet of $s n-1$ acyl and $s n-2$ acyl lyso-PC product-ion peaks because the sn-1 acyl lyso-PC ion is always more abundant than the sn-2 acyl lyso-PC ion (Fig. 2AC) [19]. For plasmalogen species, only the carboxylate anion corresponding to the sn-2 acyl substituent was detected, since the $s n-1$ substituent did not easily cleave to form an anion [19,35] (Fig 2D). However, in the case of PIsC 18:0/22:6 (Fig. 2E), the $\mathrm{MS}^{2}$ fragmentation of the selected molecular ion $\left[\mathrm{M}-\mathrm{CH}_{3}\right]^{-}$at $\mathrm{m} / \mathrm{z} 802$ shows the ion at $\mathrm{m} / \mathrm{z} 327$ corresponding to the $\mathrm{C} 22: 6$ carboxylate anion and the fragment at $\mathrm{m} / \mathrm{z} 283$, which is generated by $\mathrm{CO}_{2}$ loss, as explained above. Thus, during the interpretation of spectra from PC or PIsC containing C22:6n-3 in the sn-2 position, it is important to pay attention to the fragment at $\mathrm{m} / \mathrm{z} 283$ generated by $\mathrm{CO}_{2}$ loss by $\mathrm{C} 22: 6$ carboxylate anion, because it can be confused with the C18:0 carboxylate anion.

The PC species were characterised in bovine retina. The different PC, VLC-PC and PIsC molecular species characterised in bovine retina (Fig. 3A) are listed in Table 1. We particularly focused on the VLC-PC fraction in the retina (Fig. 3B). Identification by ESI-MS/MS showed that this fraction contained exclusively dipolyunsaturated PC species with one VLC-PUFA always in the sn-1 position and docosahexaenoic acid (DHA, C22:6n-3) exclusively at the sn-2 position. For example, as illustrated in Fig. $\mathbf{2 F}$ the product ion spectra of the demethylated molecular ion $\left[\mathrm{M}-\mathrm{CH}_{3}\right]^{-}$of $\mathrm{PC}$ 32:4/22:6 at $\mathrm{m} / \mathrm{z} 1006$ showed the two abundant ions at $\mathrm{m} / \mathrm{z} 327$ and $\mathrm{m} / \mathrm{z} 471$, corresponding to $\mathrm{C} 22: 6$ and C32:4 carboxylate anions, respectively, and the ion at $\mathrm{m} / \mathrm{z} 283$, which is generated by $\mathrm{CO}_{2}$ loss by the C22:6 carboxylate anion. Furthermore, we observed the product ions formed by neutral loss of either an FA or a ketene at $m / z 678\left(\left[\mathrm{M}-\mathrm{CH}_{3}-\mathrm{R}_{2} \mathrm{CH}-\mathrm{COOH}\right]^{-}\right), m / z 696\left(\left[\mathrm{M}-\mathrm{CH}_{3}-\mathrm{R}_{2} \mathrm{CH}=\mathrm{C}=\mathrm{O}^{-}\right)\right.$, and $m / z 552\left(\left[\mathrm{M}-\mathrm{CH}_{3}-\mathrm{R}_{1} \mathrm{CH}=\mathrm{C}=\mathrm{O}\right]^{-}\right)$. Among these three fragments, the fragment at $m / z 696$ was the most abundant and it was therefore useful for regioisomeric assignment.

We characterised 69 PC molecular species, in particular 22 VLC-PC molecular species, in bovine retina (Table 1). All these identified VLC-PC molecular species contained C22:6 in the sn-2 position and VLC-PUFA in the sn-1 position according to Aveldaño [55]. These VLC-PC species contained fatty acyl from 24 to 36 carbon chains long, with four, five or six double bonds. The majority of VLC-PC contained C32 and C34 VLC-PUFA with four, five or six double bonds. Phospholipids from human retina were also separated (Fig. 1B) using the same LC-ESI-MS conditions. The main PC and VLCPC were characterised and compared to those identified in bovine retina (Fig. 4). Thirty-six PC molecular species and in particular 13 VLC-PC molecular species were detected in significant amounts in human retina (Table 2). Similar structures of VLC-PC to those in bovine retina were characterised in human retina. C22:6 still remained in the sn-2 position and the VLC-PUFA in the sn-1 position. Moreover, as in bovine retina, the majority of VLC-PC contained C32 and C34 VLC-PUFA with four, five or six double bonds. Only traces of VLC-PC containing C30:5, C30:6, C36:5 and C36:6 were also detected but could not be quantified. 
For structural identification of VLC-PUFA, LC-MS/MS did not allow localisation of the double bonds along the carbon chain. According to previous studies, retinal C28-C36 fatty acids are polyunsaturated and belong to the $n-3$ and $n-6$ families [2,56]. The $n-6$ family of C28-C36 fatty acids has four or five double bonds, while the n-3 family of VLC-PUFA contain five or six double bonds. To check these in our retina samples, a part of the isolated VLC-PC fraction by HPLC was converted into fatty acid methyl esters (FAMEs) and analysed by GC-FID). An aliquot of FAME of the isolated VLC-PC fraction from bovine retina was then converted into DMOX derivative and analysed using GC-EI-MS (Fig. 5A). Identification was established according to previous studies [52,57,58]. For example, the mass spectra of the DMOX derivative of C32:4 (n-6) and C32:6 (n-3) are presented in Fig. 6. GC-MS mass spectra of DMOX derivative of C32:6 n-3 and 32:4 n-6 gave intense molecular ions at $m / z 521$ and $m / z 525$ respectively, and fragmentation localised the double bonds in the carbon chain. In DMOX derivatives of mono- or polyunsaturated fatty acids, a mass interval of 12 amu instead of the regular 14 amu between two neighbouring homologous fragments containing $\mathrm{n}-1$ and $\mathrm{n}$ carbon atoms of the original acid moiety indicates that a double bond exists between carbons $n$ and $n+1$ in the chain [58]. Moreover, it is important to note that a gap of $40 \mathrm{amu}$ is also observed between the two fragments containing $n-2$ and $n+1$ carbon atoms, located around the double bond. Thus, we have established the mass spectra of the DMOX derivatives of major VLC-PUFA detected in the isolated VLC-PC fraction obtained by HPLC from bovine and human retinas (Fig. 6A and 6B). In our samples of bovine retinas, as in human retinas, C30-C34 VLC-PUFA of the n-6 family had only four double bonds, while C28C36 VLC-PUFA of the n-3 family had five or six double bonds. Moreover, as expected, C32 and C34 VLC-PUFA with four, five and six double bonds seem to represent the prominent VLC-PUFA in bovine retinas as well as in human retinas. These results are in agreement with our LC-MS/MS data.

PUFA longer than C26 are suspected of having key functions in several tissues. For example, they are essential components of epidermal acylceramides and then important actors in skin barrier function $[59,60]$, whereas they were shown to be involved in sperm maturation in testis [61,62]. In the retina, C28-C36 VLC-PUFA appear to be associated with rhodopsin in photoreceptor outer segments [55] and are suspected of being involved in phototransduction processes. This hypothesis is consistent with the electroretinographic defects in the various mouse models carrying various mutations in the ELOVL4 gene [13,63-65], even if their retinas have not been fully characterised in terms of changes in C28-C36 acyl PCs.

\subsection{Quantification of the PC species in total lipids extracted from human retina}

In single-stage positive-ion ESI-MS of total lipid extracts, PC molecular species often give rise to major peaks corresponding to the sodiated molecular ions $[\mathrm{M}+\mathrm{Na}]^{+}$along with the protonated ones $[\mathrm{M}+\mathrm{H}]^{+}$. This phenomenon, also reported previously [17-19,36], complicates the analysis of PCs in biological samples. Addition of ammonium formate in the LC solvent considerably reduced the formation of sodiated adducts $[\mathrm{M}+\mathrm{Na}]^{+}(<5 \%)$ but did not eliminate them completely [31]. Alternatively, some authors included sodium or lithium salts to suppress formation of protonated ions [19,66]. However, we were not able to avoid protonated ions by post-column inclusion of lithium or sodium salts, directly in the source. In the $\mathrm{MS}^{2}$ mode, PC species showed an intense fragment at $\mathrm{m} / \mathrm{z} 184$ due to their 
choline head group. This fragment was used for precursor ion scanning, whereby the $[\mathrm{M}+\mathrm{H}]^{+}$ions of PCs are specifically detected [29,30,36]. Precursor ion scanning for $m / z 184$ selectively detects only $[\mathrm{M}+\mathrm{H}]^{+}$ions for choline-containing phospholipids, since PC molecules cationised by sodium or potassium exclusively lose their polar choline phosphate head group as a 183-Da neutral fragment instead of forming the fragment at $\mathrm{m} / \mathrm{z} 184$ [34]. To optimise the formation of this precursor, we investigated the influence of the fatty acid chain length on the intensity and optimal collision cell offset for the generation of the $m / z 184$ fragment for PC 14:0/14:0 (PC 28:0), PC 16:0/16:0 (PC 32:0), PC 18:0/18:0 (PC 36:0), PC 20:0/20:0 (PC 40:0), PC 23:0/23:0 (PC 46:0), PC 24:0/24:0 (PC 48:0), PC 16:0/18:1(PC 34:1), PC 18:0/18:2 (PC 36:2), PC 18:0/20:4 (PC 38:4), PC 18:0/22:6 (PC 40:6), PC 22:6/22:6 (PC 44:12) and PIsC 18:0/22:6 (PIsC 40:6). Collision cell offset plots were established correlating the fragment ion intensity at $\mathrm{m} / \mathrm{z} 184$ with the voltage off in the collision cell. Moreover, collision cell offset plots were also established for the more intense VLC-PUFA, PC 32:4/22:6 (PC 54:10, $\mathrm{m} / \mathrm{z}$ 1022) and PC 34:4/22:6 (PC 56:10, $\mathrm{m} / \mathrm{z}$ 1050) using the isolated and concentrated HPLC fraction containing VLC-PC. As a result, the optimal collision offset increases with increasing chain length, varying from about -30 to $-50 \mathrm{~V}$ for the precursor ions investigated. As a compromise, $-36 \mathrm{~V}$ was selected as collision cell offset.

Determination of phospholipid molecule species level requires the addition of internal standards because the ionisation efficiency between different phospholipid classes of ESI-MS may differ significantly with respect to experimental conditions. PC 14:0/14:0 $(\mathrm{m} / \mathrm{z} 678)$ and PC 24:0/24:0 (m/z 958) were selected as internal standards in the analyses of PC, PIsC and VLC-PC since these molecular species do not occur naturally in biological samples studied in this work. However, precautions were taken in this quantitative study because different molecular species are not detected with equal efficiency. Previous studies indicated that the total phospholipid concentration affect the quantification of PC species by ESI-MS/MS [29]. Therefore, we investigated the influence of these different parameters on the instrument response. First, to establish the range of linear response of our ESI-MS/MS instrument, an equimolar mixture was prepared with standards of PC 14:0/14:0, PC 16:0/16:0, PC 16:0/18:1, PC 18:0/18:0, PC 18:0/18:2, PC 18:0/20:4, PC 18:0/22:6, PIsC 18:0/22:6, PC 20:0/20:0, PC 22:6/22:6, PC 23:0/23:0 and PC 24:0/24:0, diluted from $5 \mathrm{pg} / \mu \mathrm{L}$ to $5 \mathrm{ng} / \mu \mathrm{L}$ per species (from $60 \mathrm{pg} / \mu \mathrm{L}$ to $60 \mathrm{ng} / \mu \mathrm{L}$ of total PC) in chloroform/methanol (1:1) and then injected to LC-ESI-MS. The PC mixture had a linear response of ion count versus concentration from $5 \mathrm{pg}$ to $2 \mathrm{ng} / \mathrm{\mu L}$ (from 60 $\mathrm{pg} / \mu \mathrm{L}$ to $24 \mathrm{ng} / \mu \mathrm{L}$ of total PC) (Fig. 7). Beyond this concentration, the response was nonlinear and began to plateau.

Furthermore, the acyl chain length and chain unsaturation have a significant effect on the instrument response $[28,34,36,67]$. We established a calibration curve between the intensity of the observed quasi-molecular ion species and the length and degree of unsaturation of the carbon chains. Response curves were prepared with increased concentrations of PC 16:0/16:0, PC 16:0/18:1, PC 18:0/18:2, PC 18:0/18:0, PC 18:0/20:4, PC 18:0/22:6, PIsC 18:0/22:6, PC 20:0/20:0, PC 22:6/22:6 and PC 23:0/23:0 (range, $2.5 \mathrm{pg} / \mu \mathrm{L}$ to $2.5 \mathrm{ng} / \mu \mathrm{L}$ ) and fixed concentrations of $\mathrm{PC} 14 / 14: 0(0.4 \mathrm{ng} / \mu \mathrm{L}$ ) and PC 24:0/24:0 (0.64 $\mathrm{ng} / \mathrm{\mu L})$ as internal standards. Linear calibration curves were obtained for PC species from $2.5 \mathrm{pg} / \mu \mathrm{L}$ to $2.5 \mathrm{ng} / \mu \mathrm{L}$. Our results confirmed that the instrument response for $\mathrm{PC}$ 
species decreases when the phospholipid acyl chain length is increased [28,34,36]. According to Koivusalo et al. [36], the responses remain a linear function of the acyl chain length, even at the highest concentrations. Lastly, under our conditions, the effect of acyl chain unsaturation seems to be weak. Previous studies showed that the effect of acyl chain unsaturation was less significant when the injection amount of lipid molecules is minimised [27,36]. To overcome this problem, experiments were conducted with the least amount of required material.

After having determined the effect of structural factors and lipid concentration on the instrument, we used this information to quantify the molecular species of PC and PIsC in human retina. In order to check the applicability of the method in a biological sample, samples of human retina $(12.5 \mathrm{ng} / \mu \mathrm{L})$ or blank (chloroform/methanol) were spiked with the increment level of an equimolar mixture of saturated PC 14:0/14:0, PC 18:0/18:0, PC 20:0/20:0, PC 23:0/23:0 and PC 24:0/24:0 (0.25, 0.5 or $1 \mathrm{ng} / \mathrm{\mu L}$ per species), and then analysed. An example of representative spectrum is shown in Fig. 8. These allowed us to correct for acyl chain length dependency of the instrument response. Consequently, a calibration function was then calculated and used to correct the experimental ion abundance in order to obtain the true molar abundance. With VLC-PUFA (from PC 52:9 and PC 58:10), no standards were available to calculate the calibration curve. Therefore, this curve was extrapolated from the different results obtained above as a function of the phospholipid acyl chain length and the degree of acyl chain unsaturation.

The calibration method developed was then applied to quantify PC and VLC-PC molecular species extracted from retina samples obtained from nine human donors. The phosphorus content of total lipid extracts was determined using the Bartlett and Lewis method [49] in order to standardise the concentration of all lipid extracts at $12.5 \mathrm{ng} / \mu \mathrm{L}$. A constant amount of both PC 14:0/14:0 (0.4 ng/ $\mathrm{LL})$ and PC 24:0/24:0 $(0.64 \mathrm{ng} / \mu \mathrm{L})$ were therefore added to an aliquot of the lipid extract $(12.5 \mathrm{ng} / \mathrm{\mu L})$ for the quantification. PC 24:0/24:0 was added with a known amount in order to estimate the accuracy of the MS method for every sample. The identified and quantified 36 PC species in human retinas are listed in Table 2. In most of these, 13 VLC-PUFA-containing dipolyunsaturated PC were detected and quantified. The main VLC-PC (PC containing VLC-PUFA) detected and quantified in human neural retinas were those having VLC-PUFA of 32 carbon atoms (C32:3, C32:4, C32:5 and C32:6) and 34 carbon atoms (C34:3, C34:4, C34:5 and C34:6). Dipolyunsaturated PC with 30:5, 30:6, 36:5 and 36:6 were detected but in smaller quantities.

\section{Conclusion}

In summary, qualitative and quantitative analysis of VLC-PC species was examined in this paper. An accurate method using normal-phase HPLC coupled on-line with triple quadrupole mass spectrometer was developed to characterise and quantify all PC species, including VLC-PCs in human retina and bovine retinas. Since the results from molecular and biochemical studies led to the conclusion that VLC-PUFA are involved in the pathogenesis of STD3, the method developed herein may be useful to more accurately investigate the molecular mechanisms leading to photoreceptor dysfunction and death in STD3.

\section{Acknowledgements:}


The authors would like to thank Gilles Thuret and Philippe Gain (Faculty of Medicine, Laboratory of biology, engineering and imaging of corneal graft at Saint Etienne, France) for collecting and providing retinas from human donors.

\section{References}

[1] M.I. Aveldano, J. Biol. Chem. 262 (1987) 1172.

[2] M.I. Aveldano, H. Sprecher, J. Biol. Chem. 262 (1987) $1180 .$.

[3] A. Poulos, Lipids 30 (1995) 1.

[4] N.P. Rotstein, M.I. Aveldano, Biochem. J. 249 (1988) 191.

[5] N.P. Rotstein, M.I. Aveldano, Biochem J. 249 (1988) 191.

[6] Z.Q. Zhang, Y. Wang, H.G. Vikis, L. Johnson, G.J. Liu, J. Li, M.W. Anderson, R.C. Sills, H.L. Hong, T.R. Devereux, T. Jacks, K.L. Guan, M. You, Na. Genet. 29 (2001) 25.

[7] A.O. Edwards, L.A. Donoso, R. Ritter, Invest. Ophthalmol. Vis. Sci. 42 (2001) 2652.

[8] C. Grayson, R.S. Molday, J. Biol. Chem. 280 (2005) 32521.

[9] P. Tvrdik, R. Westerberg, S. Silve, A. Asadi, A. Jakobsson, B. Cannon, G. Loison, A. Jacobsson, J. Cell Biol. 149 (2000) 707.

[10] A. Meyer, H. Kirsch, F. Domergue, A. Abbadi, P. Sperling, J. Bauer, P. Cirpus, T.K. Zank, H. Moreau, T.J. Roscoe, U. Zahringer, E. Heinz, J. Lipid Res. 45 (2004) 1899.

[11] R. Westerberg, P. Tvrdik, A.B. Unden, J.E. Mansson, L. Norlen, A. Jakobsson, W.H. Holleran, P.M. Elias, A. Asadi, P. Flodby, R. Toftgard, M.R. Capecchi, A. Jacobsson, J. Biol. Chem. 279 (2004) 5621.

[12] J.P. SanGiovanni, E.Y. Chew, Prog. Retin. Eye Res. 24 (2005) 87.

[13] G. Karan, C. Lillo, Z. Yang, D.J. Cameron, K.G. Locke, Y. Zhao, S. Thirumalaichary, C. Li, D.G. Birch, H.R. Vollmer-Snarr, D.S. Williams, K. Zhang, Proc. Natl. Acad. Sci. U S A 102 (2005) 4164.

[14] A. McMahon, W. Kedzierski, Br. J. Ophthalmol..

[15] M. Agbaga, R.S. Brush, M.N. Mandal, A., K. Henry, M.H. Elliott, R. Anderson, PNAS 105 (2008) 12843.

[16] S.S. Antollini, M.I. Aveldano, J. Lipid Res. 43 (2002) 1440.

[17] J.L. Kerwin, A.R. Tuininga, L.H. Ericsson, J Lipid Res. 35 (1994) 1102.

[18] J. Fang, M.J. Barcelona, J. Microbiol. Methods. 33 (1998) 23.

[19] X. Han, R.W. Gross, J. Am. Soc.Mass Spectro. 6 (1995) 1202.

[20] X. Han, W.G. Richard, Proceedings of the National Academy of Sciences of the United States of America 91 (1995) 10635.

[21] T. Houjou, K. Yamatani, H. Nakanishi, M. Imagawa, T. Shimizu, R. Taguchi, Rap. Com. Mass Spectom. 18 (2004) 3123.

[22] C. Beermann, M. Mobius, N. Winterling, J.J. Schmitt, G. Boehm, lipids 40 (2005) 211.

[23] A. Larsen, S. Uran, P.B. Jacobsen, T. Scotland, Rap. Com. Mass Spectom. 15 (2001) 2393.

[24] G. Issac, D. Bylund, J.-E. Mansson, K.E. Markides, J. Bergquist, J. Neurosci. Methods. 128 (2003) 111.

[25] A. Carrier, J. Parent, S. Dupuis, J. Chromatogr. A 876 (2000) 97.

[26] B. Barroso, R. Bischoff, J. Chromatogr. B 814 (2005) 21.

[27] E.J. Ahn, H. Kim, B. Chul Chung, G. Kong, M.H. Moon, J. Chromatogr. A 1194 (2008) 90.

[28 E.J. Ahn, H. Kim, B.C. Chung, M.H. Moon, J. Sep. Sci. 30 (2007) 2598.

[29] C.J. Delong, P.R. Baker, M. Samuel, Z. Cui, M.J. Thomas, J. Lipid Res. 42 (2001) 1959.

[30] W.D. Lehmann, M. Koester, E. G., K. Dietrich, Anal. Biochem. 246 (1997) 102.

[31] N. Acar, O. Berdeaux, P. Juaneda, S. Gregoire, S. Cabaret, C. Joffre, C.P. Creuzot-Garcher, L. Bretillon, A.M. Bron, Exp. Eye Res. (2009) 840.

[32] M. Malavolta, F. Bocci, E. Boselli, N.G. Frega, J. Chromatogr. B 810 (2004) 173.

[33] K.Z. Berry, R.C. Murphy, J. Am. Soc. Mass Spectrom. 15 (2004) 1499.

[34] B. Brugger, G. Erben, R. Sandhoff, F.T. Wielland, W.D. Lehmann, Proceedings of the National Academy of Sciences of the United States of America 94 (1997) 2339.

[35] F. Gao, X. Tian, W. Dawei, J. Liao, T. Wang, H. Liu, Biochim. Biophys. Acta 1761 (2006) 667.

[36] M. Koivusalo, P. Haimi, L. Heikinheimo, R. Kostiainen, P. Somerharju, J. Lipid Res. 42 (2001) 663.

[37] H. Kim, H.K. Min, G. Kong, M.H. Moon, Anal. Bioanal. Chem. 393 ( 2009$) 1649$.

[38] H. Kim, E.J. Ahn, M.H. Moon, Analyst 133 (2008) 1656.

[39] X. Han, R.W. Gross, Mass. Spectrom. Rev. 24 (2005) 367. 
[40] M. Pulfer, R.C. Murphy, Mass. Spectrom. Rev. 22 (2003) 332.

[41] X. Han, R.W. Gross, J. Lipid Res. 44 (2003) 1071.

[42] H. Kim, T.-C. Wang, L., Y.-C. Ma, Anal. Chem. 66 (1994) 3977.

[43] M. Hermansson, A. Uphoff, R. Käkelä, P. Somerharju, Anal. Chem. 77 (2005) 2166.

[44] R. Taguchi, J. Hayakawa, Y. Takeuchi, M. Ishida, J. Mass. Spectrom. 35 (2000) 953.

[45] T. Houjou, K. Yamatani, M. Imagawa, T. Shimizu, R. Taguchi, Rap. Com. Mass Spectrom. 19 (2005) 654.

[46] D.N. Heller, R.J. Cotter, C. Fenselau, Anal. Chem. 59 (1987) 2806.

[47] L. Bretillon, G. Thuret, S. Gregoire, N. Acar, C. Joffre, A.M. Bron, P. Gain, C.P. CreuzotGarcher, Exp. Eye Res. 87 (2008) 521.

[48] J. Folch, M. Lees, G.H.S. Standley, J. Biol. Chem. 226 (1957) 497.

[49] E.M. Bartlett, D.H. Lewis, Anal. Biochem. 36 (1970) 159.

[50] W.R. Morrison, L.M. Smith, J. Lipid Res. 5 (1964) 600.

[51] F. Dionisi, P.A. Golay, L.B. Fay, Anal. Chim. Acta 465 (2002) 395.

[52] L. Fay, U. Richli, J. Chromatogr. 541 (1991) 89.

[53] P. Juaneda, G. Rocquelin, P.O. Astorg, Lipids 25 (1990) 756.

[54] W.W. Christie, J. Lipid Res. 26 (1985) 507.

[55] M.I. Aveldano, Biochemistry 27 (1988) 1229.

[56] M. Such, A.A. Wierzbicki, M.T. Clandinin, Biochim. Biophys. Acta -Lipids and Lipid Metabolism 1214 (1994) 54.

[57] O. Berdeaux, R. Wolff, J. Am. Oil Chem. Soc. 73 (1996) 1323.

[58] J.Y. Zhang, Q.T. Yu, B.N. Liu, Z.H. Huang, Biomed. Environ. Mass Spectrom. 15 (1988) 33.

[59] D.J. Cameron, Z.Z. Tong, Z.L. Yang, J. Kaminoh, S. Kamiyah, H.Y. Chen, J.X. Zeng, Y.L. Chen, L. Luo, K. Zhang, Int. J. Biol. Sci. 3 (2007) 111.

[60] V. Vasireddy, Y. Uchida, N. Salem, S.Y. Kim, M.N.A. Mandal, G.B. Reddy, R. Bodepudi, N.L. Alderson, J.C. Brown, H. Hama, A. Dlugosz, P.M. Elias, W.M. Holleran, R. Ayyagari, Hum. Mol. Genet. 16 (2007) 471.

[61] N.E. Furland, E.N. Maldonaldo, M.I. Aveldano, Lipids 38 (2003) 73.

[62] M. Rabionet, A.C. van der Spoel, C.C. Chuang, B. von Tumpling-Radosta, M. Litjens, D. Bouwmeester, C.C. Hellbusch, C. Korner, H. Wiegandt, K. Gorgas, F.M. Platt, H.J. Grone, R. Sandhoff, J. Biol. Chem. 283 (2008) 13357.

[63] V. Vasireddy, M.M. Jablonski, M.N. Mandal, D. Raz-Prag, X.F. Wang, L. Nizol, A. lannaccone, D.C. Musch, R.A. Bush, N. Salem, Jr., P.A. Sieving, R. Ayyagari, Invest. Ophthalmol. Vis. Sci. 47 (2006) 4558.

[64] D. Raz-Prag, R. Ayyagari, R.N. Fariss, M.N. Mandal, V. Vasireddy, S. Majchrzak, A.L. Webber, R.A. Bush, N. Salem, Jr., K. Petrukhin, P.A. Sieving, Invest. Ophthalmol. Vis. Sci. 47 (2006) 3603.

[65] W. Li, Y. Chen, D.J. Cameron, C. Wang, G. Karan, Z. Yang, Y. Zhao, E. Pearson, H. Chen, C. Deng, K. Howes, K. Zhang, Vision Res. 47 (2007) 714.

[66] F.F. Hsu, A. Bohrer, J. Turk, J. Am. Soc. Mass Spectrom. 9 (1997) 516.

[67] C.Y. Lee, A. Lesimple, A. Larsen, O. Mamer, J. Genest, J. Lipid Res. 46 (2005) 1213.

\section{Figures legends:}

550

Figure 1: (A) LC-ESI-MS normal-phase chromatogram of the lipid extract from bovine retina. The retention time of phosphatidylethanolamine (PE), phosphatidylinositol (PI), phosphatidylserine (PS), phosphatidylcholine (PC), sphingomyelin (SM), and lyso-phosphatidylcholine (LPC) classes were 7$8.5 \mathrm{~min}, 11-12 \mathrm{~min}, 12-14 \mathrm{~min}, 15.5-22 \mathrm{~min}$, and 23-27.5 min, respectively. (B) LC-ESI-MS normalphase chromatogram of the lipid extract from human retina. The retention time of PE, PI,PS, PC, SM, and LPC classes were 7-8 $\mathrm{min}, 11-12 \mathrm{~min}, 13-14 \mathrm{~min}, 15.6-21 \mathrm{~min}$ and 23.5-27 min, respectively. The mass spectrometer was operated under full scan in the negative ion mode from 0 to $15 \mathrm{~min}$ and in the positive ion mode from $15 \mathrm{~min}$ to $40 \mathrm{~min}$.

Figure 2: Product-ion spectra of negative ions of various commercial phosphatidylcholines (PC) (collision offset, $+25 \mathrm{~V}$ ). (A) Product ion spectrum of the $\left[\mathrm{M}-\mathrm{CH}_{3}\right]^{-}$of $\mathrm{PC} 16: 0 / 18: 1$ at $\mathrm{m} / \mathrm{z} 744$. (B) Product ion spectrum of the $\left[\mathrm{M}-\mathrm{CH}_{3}\right]^{-}$of $\mathrm{PC} 18: 0 / 20: 4$ at $\mathrm{m} / \mathrm{z}$ 794. (C) Product ion spectrum of the $[\mathrm{M}$ 
$\left.-\mathrm{CH}_{3}\right]^{-}$of PC 18:0/22:6 at $\mathrm{m} / \mathrm{z}$ 818. (D) Product ion spectrum of the $\left[\mathrm{M}-\mathrm{CH}_{3}\right]^{-} \mathrm{PlsC}$ 18:0/18:1 at $\mathrm{m} / \mathrm{z}$ 756. (E) Product ion spectrum of the $\left[\mathrm{M}-\mathrm{CH}_{3}\right]^{-} \mathrm{PIsC} 18: 0 / 22: 6$ at $\mathrm{m} / \mathrm{z}$ 802. (F) Product ion spectrum of the $\left[\mathrm{M}-\mathrm{CH}_{3}\right]^{-}$of $\mathrm{PC} 32.4 / 22: 6$ at $\mathrm{m} / \mathrm{z} 1006$.

Figure 3: Negative-ion HPLC-ESI-MS analysis of phosphatidylcholine (PC) molecular species from bovine retina. The mass spectrometer was operated under full scan from 650 to 1100 uma. (A) Mass spectrum of total PC fraction including PC-containing VLC-PUFA (VLC-PC) collected from 15.2 min to $22 \mathrm{~min}$, as shown in Figure 1; (B) mass spectrum of VLC-PC fraction from $15.2 \mathrm{~min}$ to $16.8 \mathrm{~min}$, as shown in Figure 1.

Figure 4: Negative-ion HPLC-ESI-MS mass spectrum of total phosphatidylcholine (PC) fraction including PC-containing VLC-PUFA (VLC-PC) collected from $15.6 \mathrm{~min}$ to $21 \mathrm{~min}$, as shown in Figure 6. The mass spectrometer was operated under full scan from 650 to 1100 uma.

Figure 5: Partial GC-EI-MS total ion chromatograms (BPX-70 column) of (A) 4,4-dimethyloxazoline (DMOX) derivatives of the isolated VLC-PC fraction obtained from bovine retina and (B) DMOX derivatives of the isolated VLC-PC fraction obtained from human retina.

Figure 6: Mass spectra of 4,4-dimethyloxazoline (DMOX) derivatives of (A) 32:4n-6 and (B) 32:6n-3.

Figure 7: Concentration dependency of instrument responses. An equimolar mixture of 12 saturated phosphatidylcholine (PC) species was prepared, diluted from $5 \mathrm{pg} / \mu \mathrm{L}$ to $5 \mathrm{ng} / \mu \mathrm{L}$ per species (from 60 $\mathrm{pg} / \mu \mathrm{L}$ to $60 \mathrm{ng} / \mu \mathrm{L}$ of total PC) in chloroform/methanol (1:1) and then analyses using HPLC-ESI-MS by scanning for precursors of $\mathrm{m} / \mathrm{z} 184$ in the positive mode. Total peak intensity versus concentration of total PC.

Figure 8: Positive-ion HPLC-ESI-MS analysis of an equimolar mixture of four phosphatidylcholine (PC) standards ( $1 \mathrm{ng} / \mu \mathrm{L}$ each) spiked in total lipid extract from human retina $(12.5 \mathrm{ng} / \mu \mathrm{L})$ by parent ion scanning at $-36 \mathrm{~V}$ collision offset. The dashed lines indicate the dependency of instrument response on $\mathrm{m} / \mathrm{z}$. The main indicated PC species are $\mathrm{m} / \mathrm{z} 678.4=\mathrm{PC} 28: 0$ (std); $\mathrm{m} / \mathrm{z} 706.6=\mathrm{PC} 30: 0, \mathrm{~m} / \mathrm{z} 734$ $=\mathrm{PC} 32: 0, \mathrm{~m} / \mathrm{z} 760=\mathrm{PC} 34: 1, \mathrm{~m} / \mathrm{z} 790.4=\mathrm{PC} 36: 0$ (std) $; \mathrm{m} / \mathrm{z} 834=\mathrm{PC} 40: 6, \mathrm{~m} / \mathrm{z} 846=\mathrm{PC}$ 44:0 (std); $m / z 930=$ PC 46:0 (std), $m / z 958=$ PC 48:0 (std); m/z $1022=$ PC 54:10 and $\mathrm{m} / z 1050=$ PC 56:10. 

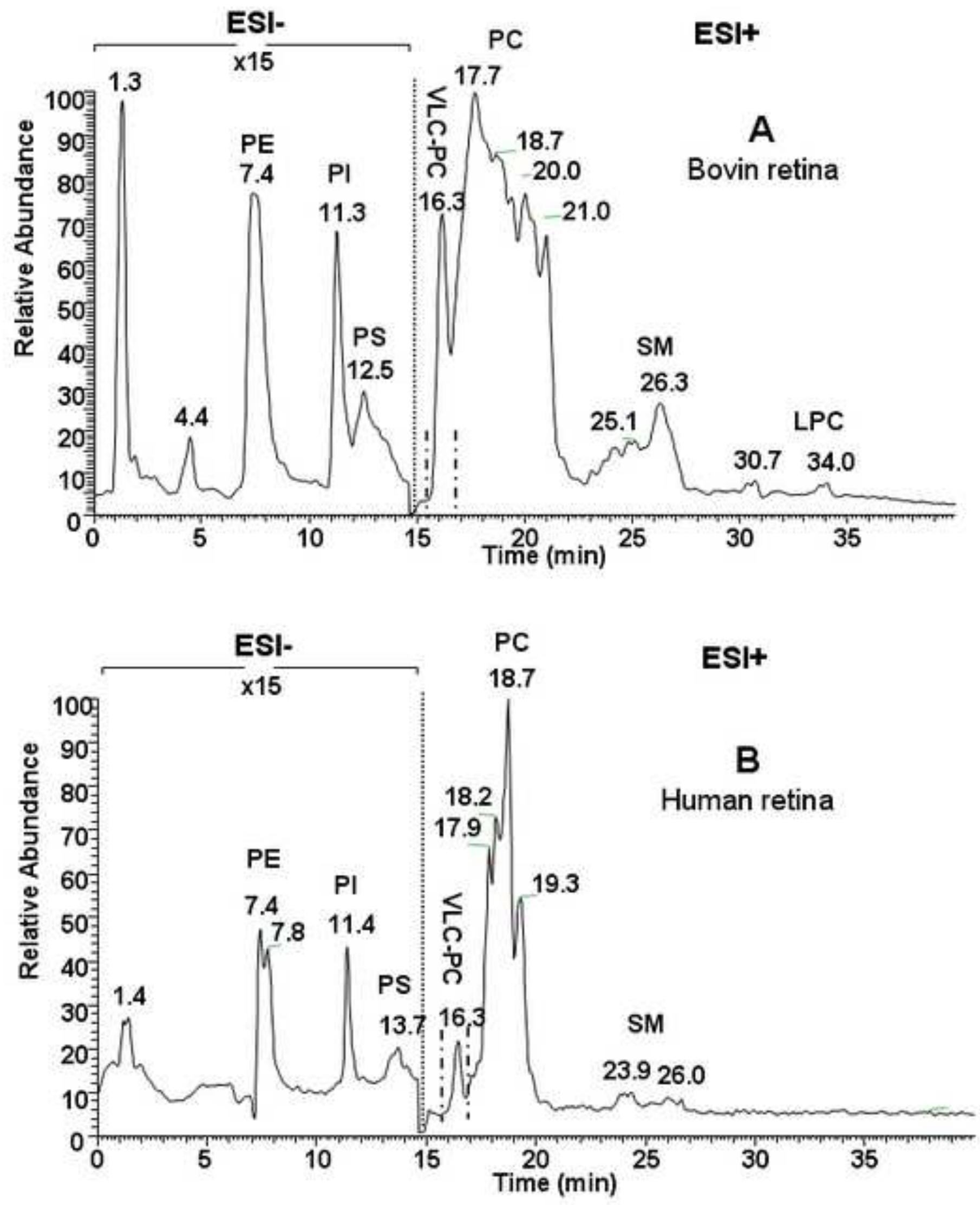

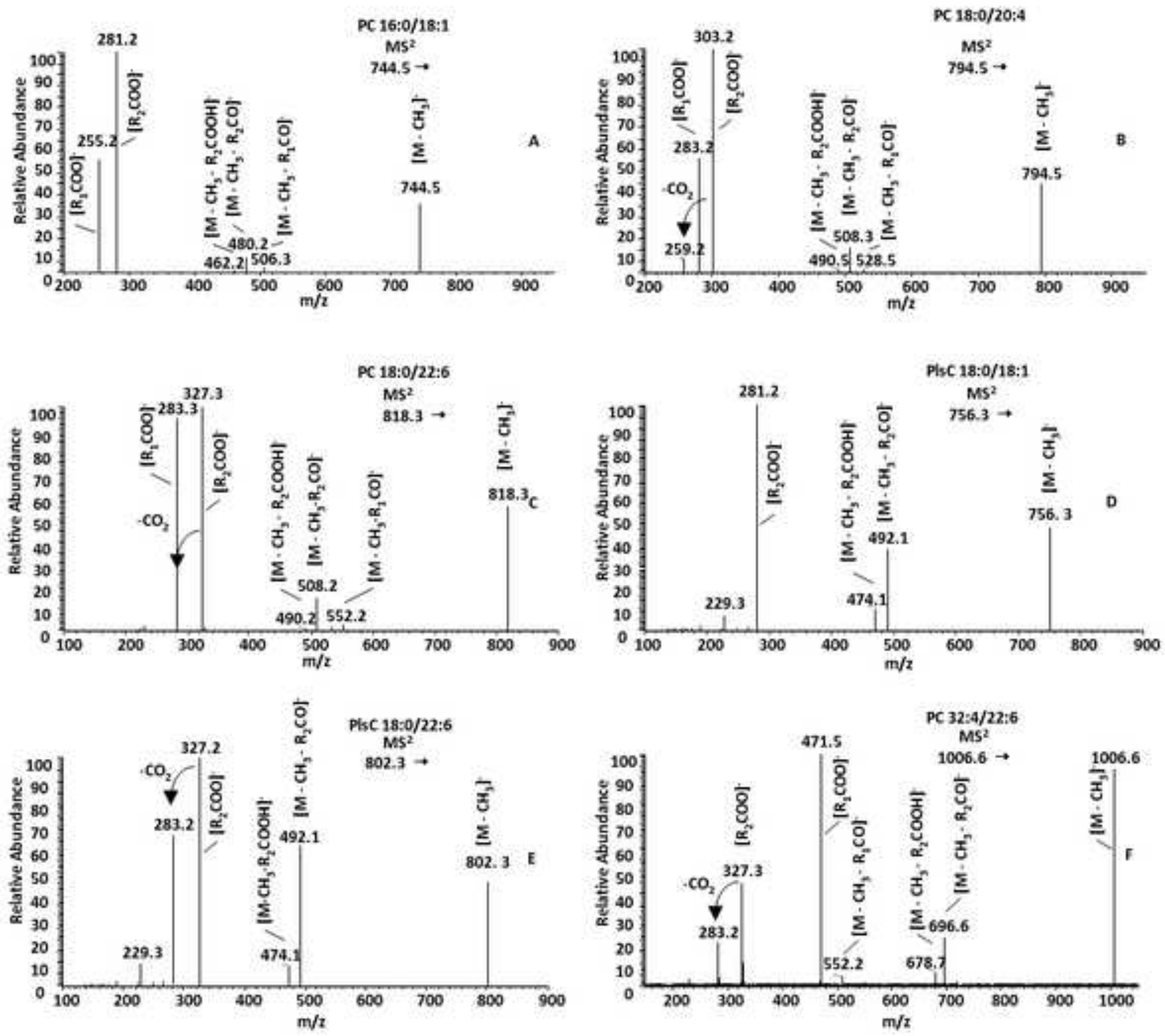

rage $1 /$ or 25 

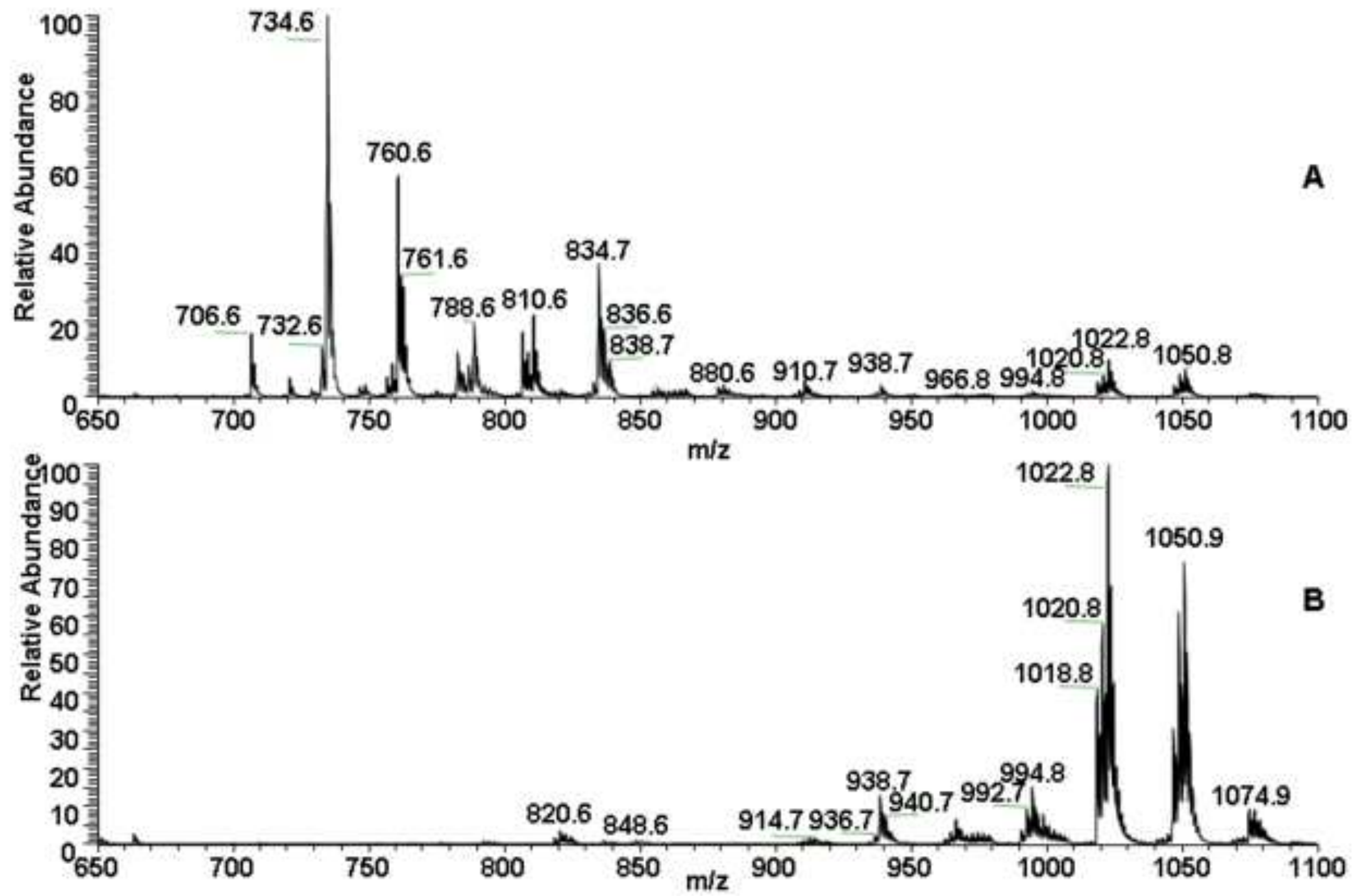


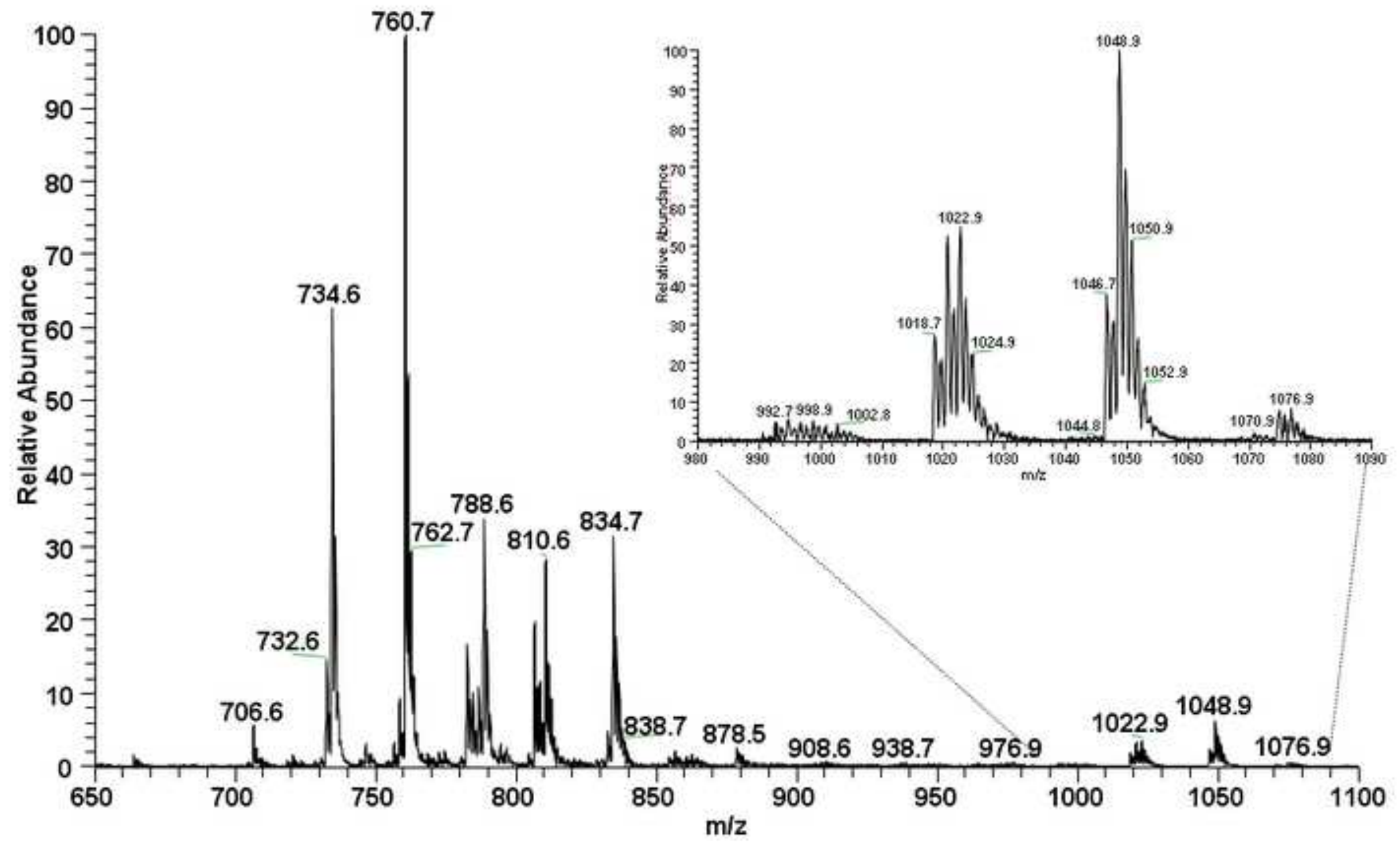



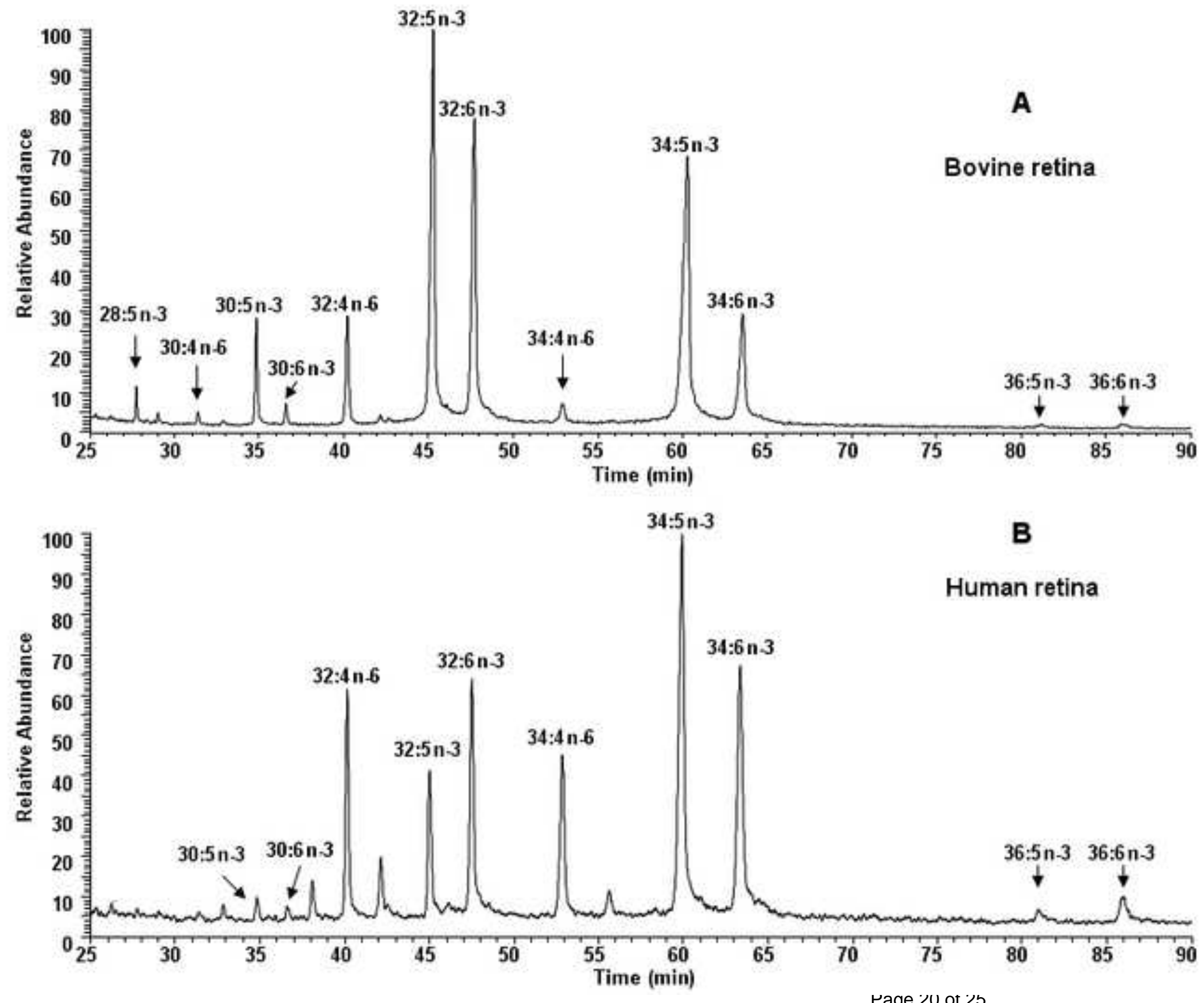

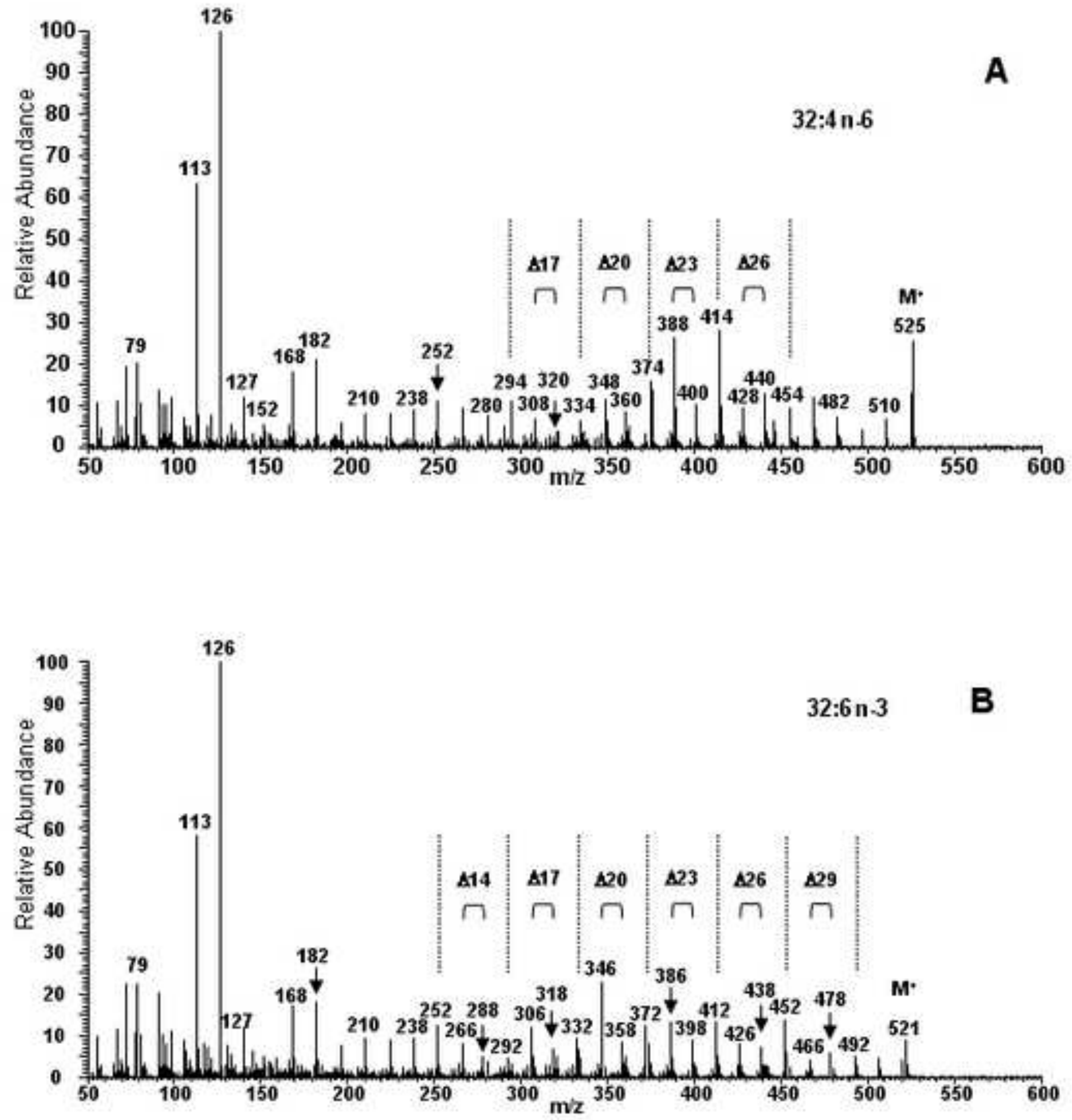


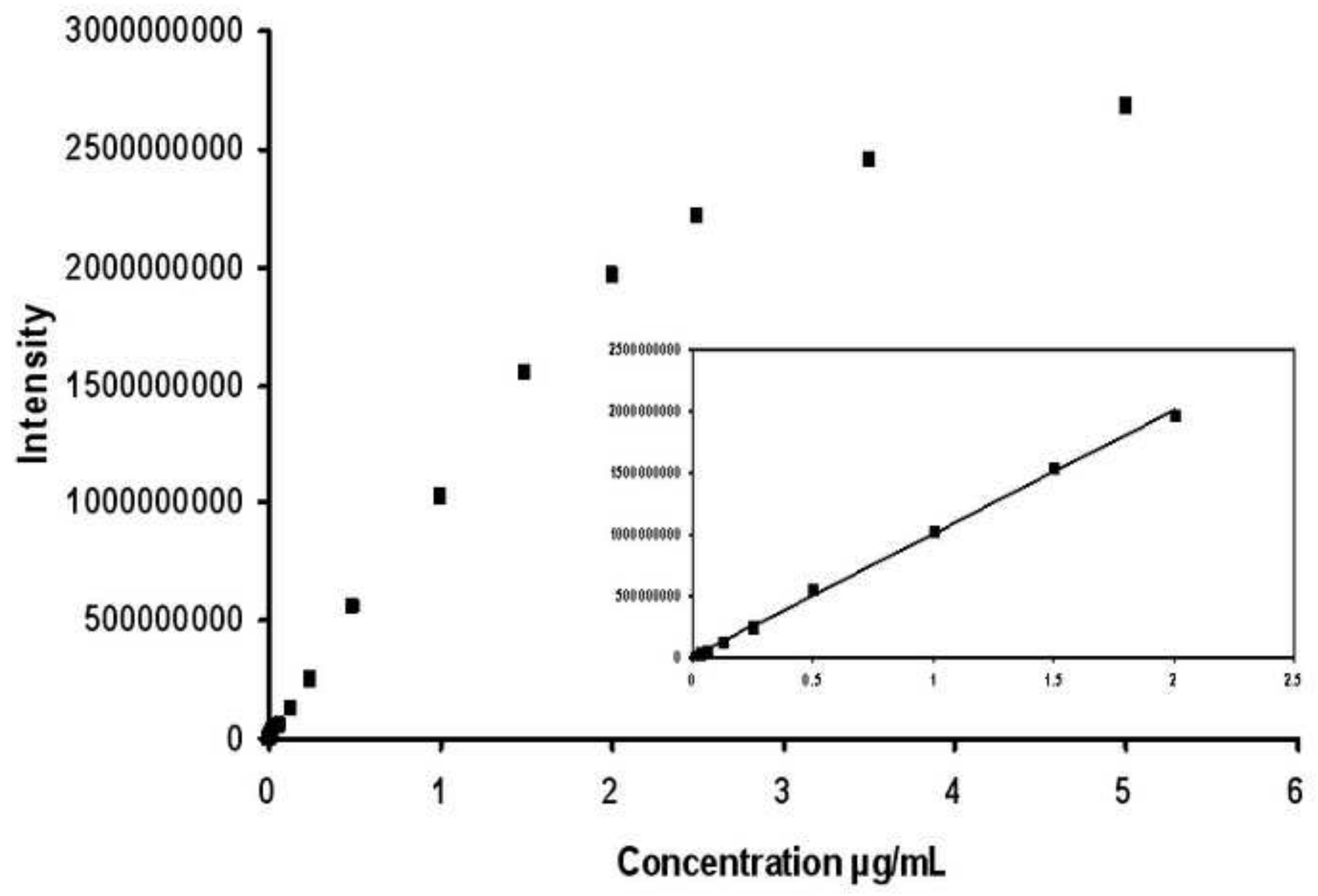

Page 22 of 25 


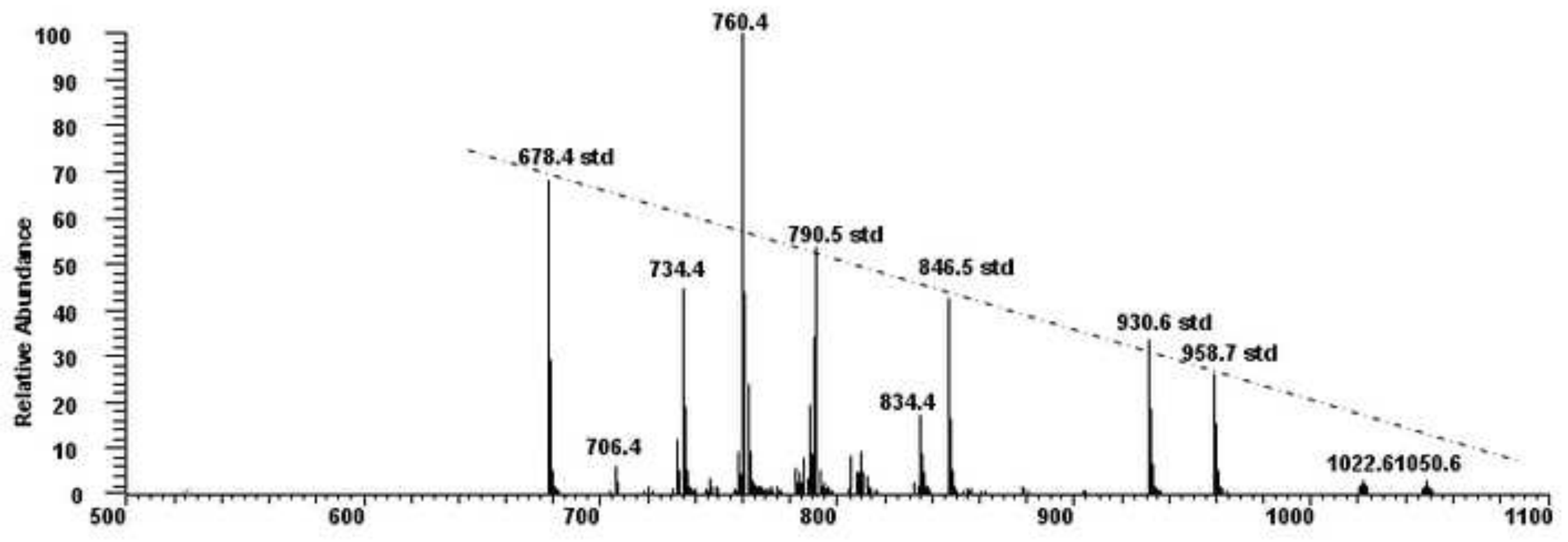


Table 1: Characterization of phosphatidylcholine molecular species in total lipid extract from bovine retina.

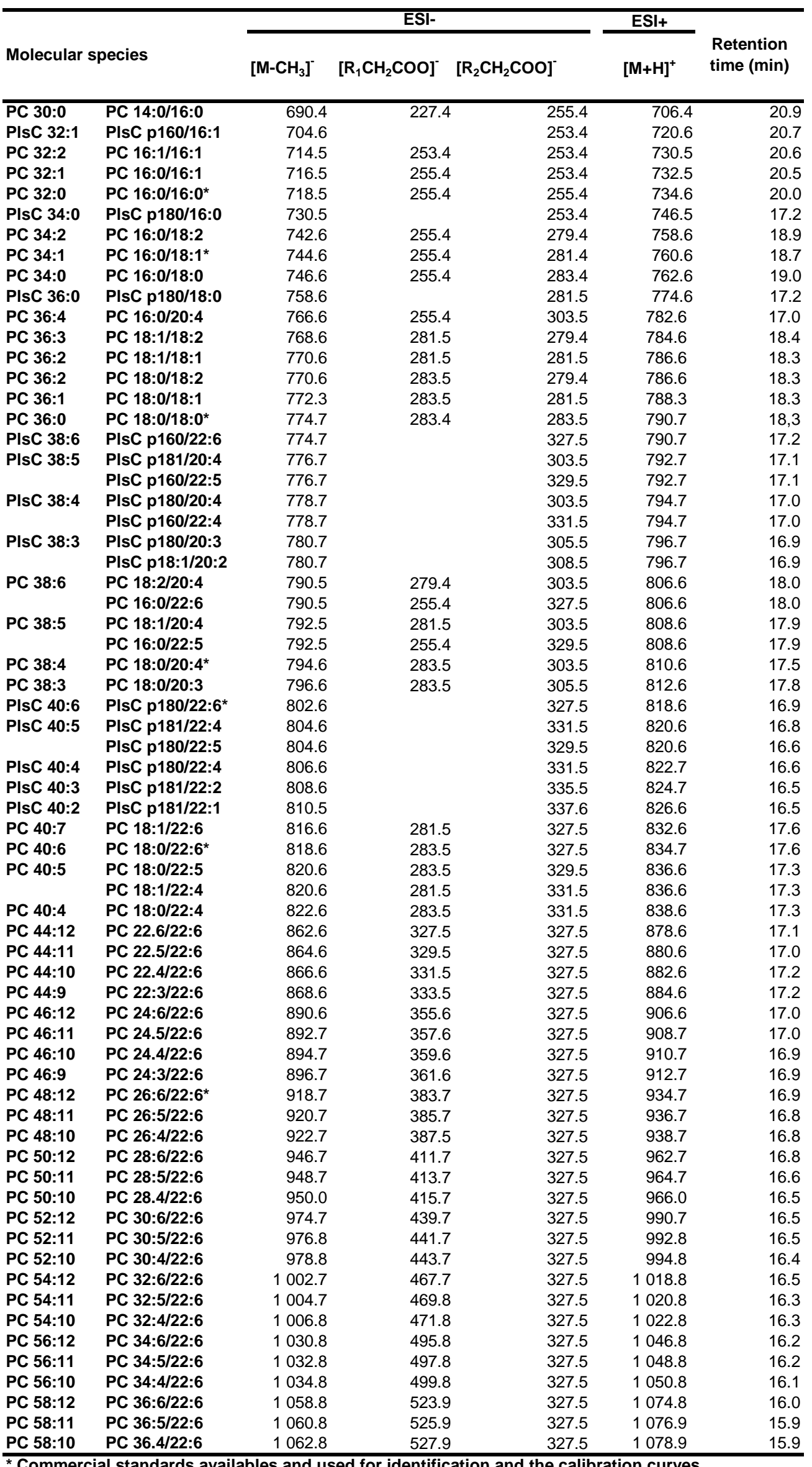


Table 2: Characterization and quantification of phosphatidylcholine molecular species in total lipid extract from human neural retina from 9 donors.

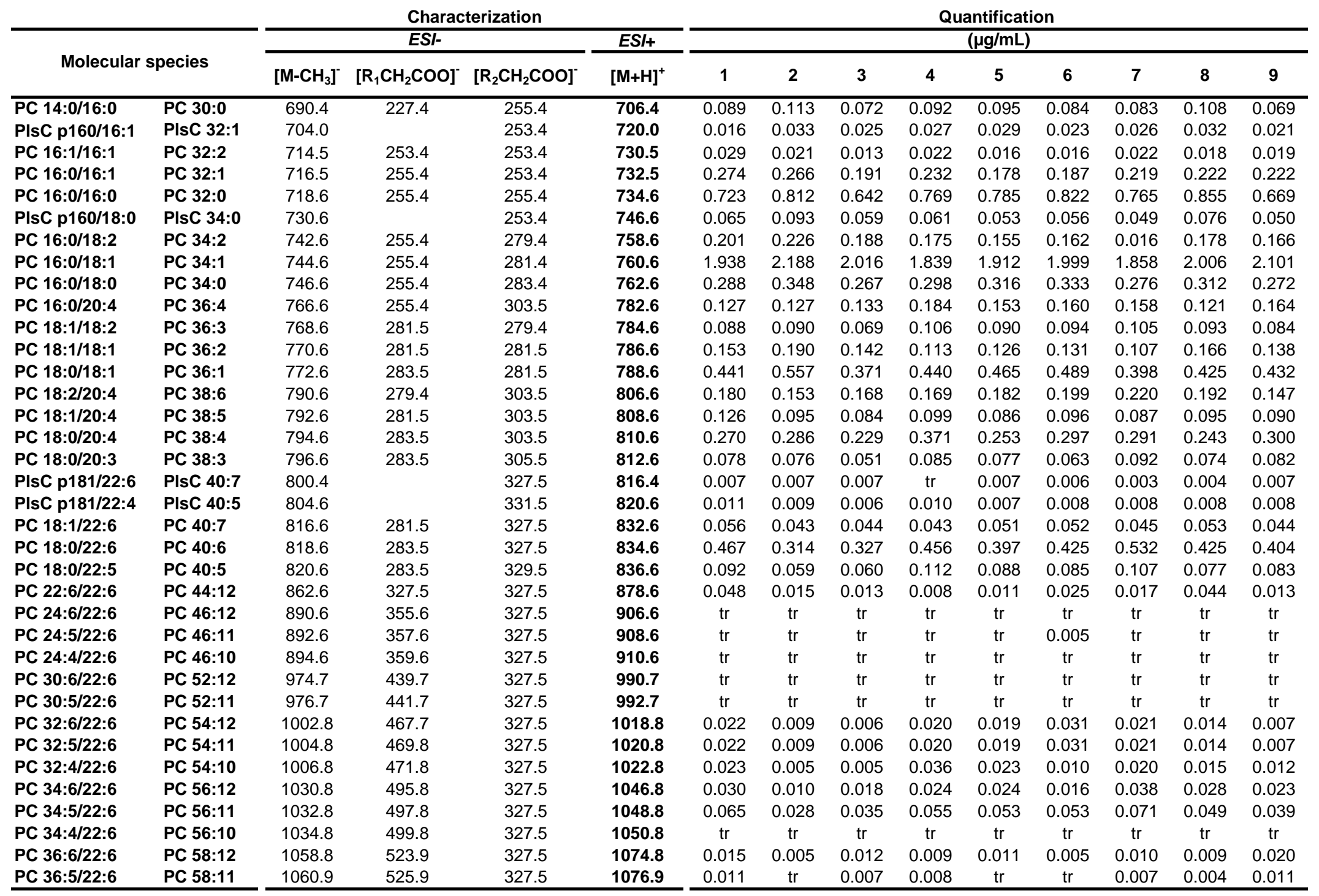

$\operatorname{tr}<0.005$ 